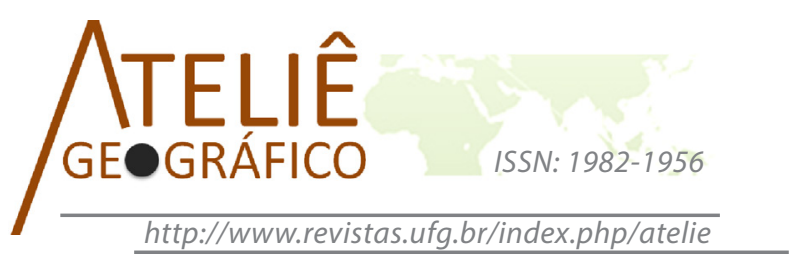

\title{
Da Esperança ao Triunfo: o estudo da formação de uma nova classe trabalhadora de Goiânia (GO)
}

\author{
Of the hope until the triumph: the study of the formation of \\ a new working class of Goiania $(G O)$
}

\section{De la Esperanza al Triunfo: el estudio de la formación de la nueva clase trabajadora de Goiânia (GO)}

\author{
Renatha Cândida da Cruz \\ Instituto Federal de Goiás - Câmpus Uruaçu \\ renathacruz@gmail.com \\ João Batista de Deus \\ Universidade Federal de Goiás \\ deus.joao@gmail.com
}

\begin{abstract}
Resumo
O objetivo principal deste artigo é tratar do processo de formação da Região Noroeste de Goiânia. Para tanto, realizou-se um amplo levantamento bibliográfico acerca das ocupações urbanas na capital goiana e elaborou-se uma periodização sobre a ampliação do espaço urbano a noroeste do centro da cidade. Os resultados obtidos permitiram verificar como uma comunidade deixa de ser um grande bolsão de pobreza para ser considerada uma representação da nova classe trabalhadora de Goiânia. A temática torna-se pertinente, visto que os bairros da Região Noroeste têm origem em sucessivas lutas coletivas pelo solo urbano e passam por um longo processo de mudanças sociais e econômicas. $\mathrm{O}$ aumento da renda ganha destaque nos estudos sobre a localidade, em que se debate se há uma nova classe média ou uma nova classe trabalhadora.
\end{abstract}

Palavras-chave: Nova classe trabalhadora. Goiânia. Ocupações urbanas.

\footnotetext{
Abstract

The main purpose of this article is figure out the process of formation in the Northwest Region of Goiania. To achieve this goal it conducted a comprehensive literature about the urban occupations in Goiânia and the development of a timeline
} 
on the expansion of urban areas to the northwest of the city center. The results of this research allowed us to understand as a community stops being a large slum to be considered a representation of the new working class of Goiania. The theme becomes relevant in sense that neighborhoods of the Northwest Region originates in successive collective struggle for urban land and go through a long process of social and economic change and how the increase in income is an important factor in studies about this place and being perceived the discussion above new middle class or new working class

Keywords: New Workin Class, Goiânia, Urban Occupations.

\begin{abstract}
Resumen
El principal objetivo de ese artículo es la comprensión del proceso de formación de la Región Noroeste de Goiânia. Para alcanzar esa meta se ha realizado un amplio levantamiento bibliográfico s obre 1 as o cupaciones u rbanas e $\mathrm{n} 1$ a capital goiana así como la elaboración de una periodización acerca de la ampliación del espacio urbano al noroeste del centro de la ciudad. Los resultados obtenidos por esta investigación permitieron comprender como una comunidad deja de ser parte de un gran cinturón de pobreza para pasar a ser considerada una representación de la nueva clase trabajadora de Goiânia. La temática se vuelve pertinente puesto que los barrios de la Región Noroeste tienen origen en sucesivas luchas colectivas por el suelo urbano y pasan por un largo proceso de cambios sociales y económicos haciendo con que el incremento de la renta sea un factor relevante en los estudios sobre la localidad, percibiéndose el debate sobre una nueva clase media o nueva clase trabajadora.
\end{abstract}

Palabras clave: Nueva clase trabajadora. Goiânia. Ocupaciones urbanas.

\title{
Introdução
}

Goiânia se tornou um dos polos de atração de migrantes em virtude de sua trajetória histórica e seu vínculo às dinâmicas goianas, o que se deve à concentração de atividades econômicas e de serviços, pois a "concentração da população acompanha a [concentração] dos meios de produção" (LEFEBVRE, 1999, p. 17). Sobretudo a partir da década de 1950, os fluxos migratórios se intensificaram e podem ser explicados por diferenciados fatores, como a construção de Brasília, as constantes propagandas sobre as oportunidades goianienses e a evolução do sistema de transportes no Estado. Entre as décadas de 1970 e 1990, os migrantes vinham de todas as regiões brasileiras, mas principalmente do interior de Goiás, do Nordeste e do Sudeste.

Além de se manter, os fluxos migratórios ampliaram-se. Santos e Silveira (2001) atribuem o aumento da migração dos trabalhadores à modernização da agricultura e à expansão da fronteira agrícola. Para Chaveiro, Calaça e Rezende (2009, p. 31), as migrações campo-cidade são intensas na década de 1980, “com queda de quase $50 \%$ de seu contingente rural". Por conseguinte, como em outras cidades, em Goiânia se observou um grande crescimento populacional, sobretudo de grandes grupos de pessoas de baixa renda que procuravam um lugar onde fosse possível uma melhoria nas condições de vida e trabalho. O resultado imediato foi o aumento das ocupações de terras por grupos que não conseguiam suportar o impacto do alto custo de vida, aliado aos baixos salários, aos altos aluguéis e à ausência de moradia digna. 
Oliveira e Peixoto (2009) asseguram que, para compreender a dinâmica de Goiânia atualmente, é necessário voltar a 1947, quando o parcelamento do solo ainda era definido pelo seu planejamento original. A mancha urbana estava restrita ao Setor Central e a alguns bairros, como os Setores Sul, Oeste e o antigo Bairro Popular, atual Setor Central. Assim, as ocupações remontam às primeiras décadas da capital goiana, quando havia uma ausência de áreas destinadas a construções populares para atender à grande quantidade de pessoas que chegavam à nova capital. Ainda na década de 1970, algumas dessas ocupações surgidas nas décadas anteriores não haviam sido regulamentadas e serviços básicos inexistiam. Alguns dos acampamentos de trabalhadores da época das construções dos prédios públicos da cidade deram origem a ocupações que foram extrapolando os limites originais da cidade. Oliveira (2002) chama esse momento de "tempo das ocupações individuais e voluntárias", que teriam se iniciado ainda na primeira década de existência da cidade de Goiânia e perdurando por tempo indeterminado.

Mesmo sendo uma realidade goianiense desde a sua fundação, as ocupações urbanas tornaram-se sistemáticas a partir de 1979, a noroeste do centro da cidade na porção rural. A luta pela terra exigiu do Estado uma ação imediata e enérgica para resolver o problema da moradia. Nas décadas que se sucederam, na Região Noroeste, houve a ampliação do espaço ocupado, seguindo a lógica dos loteamentos sem regularização por parte do Poder Público. No contexto mais recente, há loteamentos aprovados pela Prefeitura, além de um grande número de conjuntos residenciais fechados.

A partir de 2002, iniciou-se no país um estudo sobre o que foi chamado de "nova classe média", visto que um grande número de pessoas apresentava uma melhoria na renda familiar, deixando a pobreza extrema e a consequente preocupação com a fome e passando a apresentar um diferenciado padrão de consumo e comportamento social. Esse momento equivale à fase mais recente na ocupação da Região Noroeste, onde o padrão de consumo e a renda estimularam a categorização do grupo como deixando de ser um grande bolsão de pobreza e sendo chamado de nova classe trabalhadora. Instituições como Fundação Getúlio Vargas (FGV) atribuem essa mudança a diferentes fatores, mas, principalmente, às políticas nacionais de assistência social, ao aumento da renda e dos postos de trabalho formais, além da ampliação do acesso aos cursos técnicos, tecnológicos e superiores, observados a partir do ano mencionado. Essas e outras ações possibilitaram o aumento considerável na renda das famílias brasileiras e, nesse caso em particular, também das famílias da Região Noroeste da cidade de Goiânia.

Para alcançar os objetivos propostos, este trabalho foi norteado por algumas etapas metodológicas. Iniciamos com o levantamento de literaturas sobre as ocupações urbanas de Goiânia desde seus primórdios até o contexto das ocupações urbanas da Região Noroeste, ou seja, de 1933 a 1979. Esse caminho nos permitiu problematizar que a ausência de políticas públicas para a moradia da classe trabalhadora de baixa renda levou a população a buscar a ocupação dos fundos de vale como alternativas e submeter-se a condições precárias de vida, circulação na cidade e de subempregos. $\mathrm{O}$ passo seguinte foi a compreensão do cenário nacional no que se refere às condições de vida e trabalho da população de baixa renda. O conhecimento desse parâmetro permitiu conhecer os fatores de influência no cenário local, ou seja, o agravamento da situação da 
moradia nas cidades brasileiras. Seguimos com o esforço em definir uma periodização da ocupação da Região Noroeste, o que se fez necessário para uma melhor compreensão da dinâmica espacial. Santos e Silveira (2001, p. 23), ao definirem uma periodização para a história do território brasileiro, afirmam ser essa uma ação essencial para o entendimento da temática, mas esclarecem que há riscos quando se tenta organizar o tempo histórico ao mesmo tempo uno e diverso.

A partir dessa reflexão, para definir as fases de ocupação da Região Noroeste de Goiânia, procuramos criar uma cronologia baseada nos principais marcos que referenciaram cada período. Representando cada fase, adotamos o nome de algum bairro que se tornou destaque em cada momento, para que se possibilitasse compreender a simbologia dos nomes desses bairros. As fases de ocupação da Região Noroeste foram chamadas de Esperança, Finsocial, Vitória, Triunfo e uma fase intermediária, denominada Tremendão.

A fase Esperança é a de início do movimento de luta coletiva pela terra urbana entre o período de 1979 e 19881, quando ocorreram as ocupações de áreas que futuramente foram conhecidas como Jardim Nova Esperança, Jardim Boa Sorte e Jardim Boa Vista.

A fase Finsocial, entre 1982 e 1987, corresponde ao momento de intervenção estatal com a criação dos assentamentos urbanos Vila Finsocial, Vila Mutirão e Jardim Curitiba.

Vitória, a fase seguinte, compreendida entre os anos de 1988 e 2001, refere-se ao período em que ocorreu a ampliação de seu espaço com bairros cada vez mais distantes do centro da cidade e em conurbação com o município de Goianira.

A fase mais atual é a Triunfo. Corresponde ao período entre 2002 e 2010, em que se observam intensas mudanças sociais e econômicas, o que levou à associação da região a uma nova classe trabalhadora, erroneamente chamada de nova classe média, conforme Pochmann (2010) e Souza (2010).

Há ainda uma fase intermediária, chamada de Tremendão, que se refere à associação da pobreza e das mazelas sociais com ações discriminatórias com os moradores da região.

Os fatos que precedem essas fases serão tratados como fase gestacional. Almejamos, com essa análise cronológica, compreender as nuances do tempo histórico da formação da Região Noroeste de Goiânia, mesmo estando cientes das defasagens e das variáveis sem sincronia, e perceber as continuidades espaciais, para ter clareza da realidade atual.

\section{Períodos da área estudada}

\section{Esperança: a fase embrionária, de 1979 a 1981}

A primeira fase, chamada de Esperança, é a etapa embrionária da Região Noroeste, compreendida entre os anos de 1979 e 1981. É a fase originada de uma ocupação sistematizada feita por um pequeno grupo de pessoas que se fixou numa área entre a Vila João Vaz, o Setor Cândida de Morais e o Bairro Jardim Balneário Meia Ponte, bairros da 
periferia a noroeste do centro goianiense, em área rural, próximo a conjuntos de chácaras de recreio. E assim surge Esperança. Era o sonho da casa própria, mesmo que a família necessitasse se sujeitar a condições precárias de habitação e a longas distâncias de seus locais de trabalho. A casa própria é, num primeiro momento, apenas um pedaço de chão na cidade, onde seria possível montar as primeiras estacas, os primeiros alicerces de uma possível moradia. Acerca da temática, Rodrigues (1994, p. 47) assim entende:

Para as camadas populares, uma questão fundamental é a segurança de um teto, porque mesmo se eventualmente ficarem desempregados estarão seguros pelo fato de terem onde morar. Mesmo quando se consideram os arremedos de cidade onde moram, e são proprietários, a terra/casa é uma garantia de ter seu lugar na cidade, nos períodos mais difíceis.

Conforme já afirmamos, as ocupações urbanas ocorriam em Goiânia desde sua fundação. As famílias eram retiradas das áreas centrais e alocadas em pontos mais distantes, inclusive em outras cidades da atual Região Metropolitana. Rodrigues (1994, p. 46) analisa:

As ocupações demonstram mais uma vez que a busca do onde e do como morar implica a luta pela sobrevivência, pela cidadania, uma capacidade de resistência, pela cidadania, uma capacidade de resistência, que desmistifica o mito da apatia dos trabalhadores. (Grifo da autora).

A tentativa de morar em Goiânia era a condição para a manutenção do emprego, como assegura Alves (2002, p. 85), sobretudo pela precária condição de circulação entre as cidades próximas a Goiânia:

Por causa da importância de seu mercado de trabalho e a expectativa dos migrantes na obtenção de melhores condições de vida e de trabalho, Goiânia é a cidade que depois de Brasília possuía maior participação relativa de migrantes em sua força de trabalho total em 1980 (79,4\%), isto é, mais de 70\% do crescimento do número de trabalhadores ocorreu por causa dos migrantes. Além do mais, o excedente de migrantes cumpre a função de manutenção de uma mão-de-obra abundante e barata disponível para esses mercados, uma vez que Goiânia apresenta o maior percentual da força de trabalho migrante com até dois salários mínimos, sobretudo os recém-chegados, que não conseguem nem um salário mínimo [...].

A luta coletiva pela terra, iniciada em julho de 1979 com a ocupação de uma área de pouco mais de vinte e seis alqueires, deu origem ao atual bairro Jardim Nova Esperança. Um destaque para o período é que a ocupação ocorre no contexto da Ditadura Militar, quando os movimentos sociais são duramente repreendidos por intermédio da ação policial, caracterizando-se também pela ausência de diálogo e pelo uso da força física. Dessa forma, por vezes, o grupo se dissolvia, o que exigia iniciar a luta novamente, como mencionado nos estudos de Rodrigues (1994, p. 45):

Algumas vezes estas ocupações têm sido violentamente reprimidas. Freqüentemente se efetuam as desocupações. Nesses casos, dizem os desalojados, "é começar outra vez", porque outro lugar para "ir não tem 
não”. Nas desocupações está presente um forte aparato policial e é comum a violência para "limpar a área" e reintegrar a propriedade. É interessante notar que o processo chama-se "reintegração de posse", quando o que acontece é "reintegração de propriedade", porque, na verdade, detém a posse quem a está ocupando. Mas se "reintegra" o símbolo dessa posse que é a propriedade.

Para Gohn (2007), o ano de 1980 foi marcado por um novo panorama dos movimentos sociais urbanos, graças ao grande número de movimentos e agrupamentos populares dos dois anos anteriores, sobretudo com a insatisfação em face do aumento das contradições urbanas. Refere a autora:

Os anos 80 trarão um panorama novo na prática e na teoria sobre os movimentos
sociais populares urbanos. Na prática, surgem novas lutas pelo acesso à terra
e por sua posse, pela moradia, expressas nas invasões, ocupações de casas e
prédios abandonados, articulação dos movimentos dos transportes, surgimento
de organizações macro entre as associações de moradores, movimentos
de favelados ou novos movimentos de luta pela moradia, movimentos de
desempregados, movimentos pela saúde. (GOHN, 2007, p. 278).

Como dissemos, a consequência imediata das ocupações urbanas era a ação repressiva por parte da polícia. A ação repressiva veio com a destruição dos barracos. Logo após, um grupo de pessoas reuniu-se e, com a orientação da Igreja Católica, organizaram uma associação de bairro no local, mostrando a esperança de permanência na área. As primeiras moradias na ocupação do Jardim Nova Esperança se iniciaram com os barracos de lona e depois passaram a ser construídas com alvenaria. A prefeitura iniciou a negociação para aquisição da área e posterior venda dos lotes, mas a busca dos trabalhadores era pela doação desses lotes, visto que eram trabalhadores de baixa renda. Eram “[...] trabalhadores rurais que tiveram que abandonar as lavouras, despejados pelos próprios patrões, e a maioria de nós, hoje, trabalha na construção civil e as mulheres são domésticas, lavadeiras, ou trabalhavam em empresas de limpeza" (A VOZ DOS TRABALHADORES, 1979, p. 8).

A violência da repressão e sua divulgação nos principais meios de comunicação da capital ampliaram as parcerias, os auxílios e doações de material de construção e alimentos, fato que contribuiu para pressionar as autoridades a demonstrarem uma postura menos repressiva na ocupação do Jardim Nova Esperança. Essa fase é marcada ainda pelas manifestações de diferentes grupos de pessoas de baixa renda, principalmente apoiados pela Igreja Católica, o que, em 6 de novembro de 1979, possibilitou a desapropriação da área ocupada, mediante documento assinado pelo prefeito de Goiânia. Com a desapropriação da área, os moradores conseguiram uma segurança de permanência. Para Oliveira (2002), é nesse momento que houve a negação do poder institucional, pois os moradores se recusaram a aceitar o financiamento das casas pelo Banco Nacional da Habitação (BNH), um critério fundamental para a delimitação das ruas e a infraestrutura do bairro pela prefeitura. Sobre a política habitacional esclarece Rodrigues (1994, p. 57):

A política habitacional emerge com o propósito de diminuir o déficit habitacional e gerar novos empregos com o aumento das construções. Como a indústria de construção civil utiliza mão-de-obra em larga escala, incentivar a 
indústria de construção é também tentar atenuar a crise econômica. Ao mesmo tempo difunde mais a ideologia da "casa própria", contribui para a "estabilidade social" e torna os proprietários "aliados da ordem", como disse o então Ministro Roberto Campos.

O movimento de Esperança é marcado por essa resistência em financiar os lotes ou mesmo as habitações, e os moradores assumem a construção sem a intervenção do Estado e das instituições financiadoras, optando pela autoconstrução. Sobre a autoconstrução, analisa Rodrigues (1994, p. 31):

A autoconstrução é executada nos períodos que deveriam ser destinados ao descanso do trabalhador, para repor as energias, mas, na verdade, "descansase" trabalhando, "carregando pedras". Esse é o lema do autoconstrutor por vários anos. [...] $\mathrm{Na}$ autoconstrução, recai sobre as costas do trabalhador um sobretrabalho.

O movimento popular urbano do Jardim Nova Esperança tomou repercussão nacional e recebeu apoio de diversos segmentos da sociedade, dentre eles sindicatos de trabalhadores rurais, equipes de direitos humanos, Federação de Trabalhadores da Agricultura, sociedade civil, estudantes, religiosos etc. A partir do Jardim Nova Esperança, a esperança é reforçada com a desapropriação da área, deixando transparecer que é possível continuar a luta, por meio de outras ocupações, pois a área delimitada para as moradias não conseguia atender à crescente demanda. A possibilidade de conseguir uma moradia é potencializada quando os moradores do Jardim Nova Esperança deixam de sentir a repressão policial e começam a receber os primeiros serviços públicos. Para Oliveira (2002, p. 125), essa luta por moradia iniciada com o Jardim Nova Esperança significou o "fim do silêncio e da dicotomia entre o público e o privado para a sociedade goianiense".

Finsocial: a fase das intervenções estatais, de 1982 a 1987

O período entre 1983 e 1987 é marcado pelo discurso da necessidade de desenvolvimento de programas de acesso à moradia em face das crescentes ocupações urbanas. Em 1982, com o parcelamento de uma área próxima ao Jardim Nova Esperança e posterior a outras duas ocupações, Jardim Boa Sorte e Jardim Boa Vista, dá-se início ao período das ações estatais na Região Noroeste.

Essa segunda fase é dividida em três momentos. O primeiro momento inicia-se com a Vila Finsocial, que recebe esse nome a partir de um projeto do governo federal com finalidades sociais, dentre elas a moradia. O fato de se celebrar o início do processo de um assentamento urbano, feito pelo governo estadual no estádio Serra Dourada e com a realização de sorteios para a escolha dos beneficiados cadastrados previamente na ocupação do Jardim Boa Vista e de outras ocupações de Goiânia, já demonstrava o caráter eleitoreiro, como assinalado por Oliveira (1999), que assumiu durante as intervenções estatais.

O que vem a seguir são outros dois movimentos coletivos de luta pela moradia, chamados de Jardim Boa Sorte e Jardim Boa Vista. As duas ocupações tinham a mesma 
finalidade, mesmo sem qualquer documento que lhes assegurasse o direito à propriedade do bem urbano. Os ocupantes do Jardim Boa Sorte sofreram dura repressão, chegando a serem chamados de "Malvinas". Já o Jardim Boa Vista consegue o reconhecimento estatal e, conforme Moysés (2004), trata-se da terceira etapa das ocupações urbanas. As famílias que não conseguiram seu lote no Jardim Nova Esperança procuraram alternativas na própria região e assim o Jardim Nova Esperança passa a ser o ponto de partida para a esperança da moradia em Goiânia no referido período.

Em junho de 1982, o movimento já contava com oitocentas pessoas. No dia 13 do referido mês, no horário de um dos jogos da Copa do Mundo, uma grande operação tenta a expulsão das pessoas na área de posse da Fazenda Caveiras. A ação resultou em prisões, agressões e na morte do fotógrafo Joel Marcelino de Oliveira, que instigou vários setores da sociedade sobre as intenções das autoridades acerca das posses em Goiânia.

Após a ação, a Secretaria de Segurança Pública emitiu uma nota lamentando a morte do fotógrafo Joel Marcelino, fato que pressionou as autoridades a agir mais prontamente diante da ocupação. $\mathrm{O}$ terreno de vinte alqueires não podia ser transformado em chácara, nem em indústria, e assim restou lotear a área. A proprietária iniciou uma negociação com a prefeitura para a venda da área. O jornal Diário da Manhã, de 18 de junho de 1982, divulgou que na cidade de Goiânia havia quarenta e três invasões com mais de vinte mil famílias, perfazendo cerca de cento e cinquenta mil habitantes. Segundo Oliveira (2002), o surgimento da área de posse na Fazenda Caveiras suscitou uma discussão sobre a defesa da propriedade privada, do Estado e do direito coletivo, mesmo com a impressão de que havia uma resistência em estudar as formas de resolver a situação de tantos movimentos de luta pela terra urbana. Ainda em junho de 1982, cerca de 2.500 posseiros urbanos foram cadastrados no Jardim Boa Vista. No cadastramento, foi verificado que havia lotes com tamanhos diferentes. A primeira ação posterior ao cadastramento foi estipular que cada lote deveria ter $300 \mathrm{~m}^{2}$ e o excedente seria destinado a outro posseiro, com lote menor ou mesmo a quem ainda não tinha um local, segundo o jornal A Voz dos Trabalhadores (1979).

O segundo momento dessa etapa se dá em 1983, no governo de Iris Rezende, que percebe a demanda pela moradia e o marketing realizado com a Vila Finsocial e cria um projeto destinado à construção de moradias populares de baixo custo, pouco extensas e com lotes reduzidos - o Programa de Desenvolvimento Social Participativo (Prodespar). O grande marketing utilizado durante e por esse projeto era a construção de mil casas em um dia, iniciando-se em Goiânia e posteriormente se estendendo para o Estado de Goiás. As moradias foram feitas de placas de concreto, sem alicerce e sem o aval do Conselho Regional de Engenharia e Arquitetura (CREA), mas com uma grande aclamação popular, dando origem à Vila Mutirão:

O governador definiu como órgão responsável, para solucionar a questão habitacional, a Companhia de Desenvolvimento do Estado de Goiás (COTEG), que organizou a Diretoria de Planejamento e concentrou a equipe de técnicos para implementar o Programa de Desenvolvimento Social Participativo (Prodespar), cujo objetivo, entre outros, era o de "incorporar as potencialidades de cada família, numa ação conjunta com o poder público", para atuar no campo 
da habitação popular, fomentando a realização de mutirões. Assim o programa desenvolveu o projeto Mutirão da Moradia, utilizando uma forma econômica de construir por meio da prática do mutirão, pois Íris queria a comunidade como coparticipante do processo. (FREITAS, 2007, p. 26).

O projeto da Vila Mutirão gerou resistências de técnicos e membros da comunidade em geral, pois acreditavam que a construção de casas na capital destinadas às pessoas mais carentes poderia agravar o quadro migratório, atraindo ainda mais pessoas para a capital. Assim, a Vila Mutirão é criada numa área distante do centro da cidade e em direção oposta ao crescimento de Goiânia. Com a delimitação da área, restava estipular como seria realizado o projeto. O objetivo era construir o maior número de casas em um curto espaço de tempo com material de fácil manuseio, ocupando um pequeno espaço e proporcionando rápida montagem. Nesse sentido, as casas seriam feitas de placas entremeadas por barras de concreto com duas portas de acesso, uma na porção central e uma na posterior, três janelas, um número diferencial de cômodos e dimensões. Quatro modelos foram cogitados para serem adotados na Vila Mutirão. Um modelo era composto por um quarto, uma sala de $9,89 \mathrm{~m}^{2}$ e uma cozinha de $5,58 \mathrm{~m}^{2}$, com área total de $25,26 \mathrm{~m}^{2}$. Outro projeto possuía dois quartos e uma sala com $9,89 \mathrm{~m}^{2}$ e uma cozinha de $5,56 \mathrm{~m}^{2}$, perfazendo $35,25 \mathrm{~m}^{2}$. Inúmeras questões nortearam a Vila Mutirão. Uma delas foi a ausência de estudos sobre os riscos de casas feitas com placas e sem orientação técnica adequada. Ressalta-se que a proposta de moradia não contemplava banheiro no interior das residências, o que colocava as famílias em situação de precária condição sanitária. Havia ainda a insalubridade que o material das construções provocava, visto que as casas ficavam muito quentes durante o dia e muito frias à noite, além dos riscos apontados em todo o processo:

[...] muita coisa foi feita de improviso, sem tempo para checar e avaliar todo o processo e até com muita possibilidade de riscos. A própria legalização junto ao Conselho Regional de Engenharia e Arquitetura (Crea) foi inusitada, pois a Codeg não queria assumir o risco e a responsabilidade de uma construção realizada por uma pessoa sem experiência. Houve dúvidas, na época, sobre como registrar a construção pelo processo de mutirão, procedimento que fugia a todas as regras de anotação de responsabilidade técnica. (SILVA, 2014, p. 48).

A terceira intervenção acontece em 1987, com o Jardim Curitiba, que não teve tanto clamor, nem ampla divulgação como na Vila Finsocial e na Vila Mutirão. O diferencial no Jardim Curitiba também se dá com o rompimento da nomenclatura dos bairros como reflexo da história de luta e de projetos sociais. Essa observação é percebida apenas nas avenidas, como a Avenida do Povo, por exemplo. O assentamento do Jardim Curitiba iniciou-se em 1987 com área adquirida pela Companhia de Habitação de Goiás (Cohab), atual Secretaria Goiana de Habitação, e pela Companhia de Saneamento de Goiás (Saneago), ambas as empresas estatais. Nas quatro etapas de sua implantação, totalizaram-se pouco mais de 4.100 lotes, configurando-se no bairro com menor infraestrutura na gênese da ação estatal. Sem saneamento básico, asfaltamento, contava apenas com uma pequena rede elétrica. Ainda hoje, é um grande loteamento irregular. A regularização fundiária é apenas parcial e a entrega das escrituras geralmente ocorre em momentos de intervenção estatal na região. 
De acordo com Oliveira (1999), as ocupações continuavam a acontecer em diferentes pontos da cidade, mas também nas proximidades dos assentamentos urbanos da Vila Mutirão e Finsocial. Com isso, o Jardim Curitiba passou a ter quase cinco mil lotes em quatro etapas num período de dez anos. As ocupações deram origem também a outros assentamentos em outras áreas da cidade, assim como em cidades da Região Metropolitana de Goiânia. Na Região Noroeste, surge outro parcelamento, na fazenda São Domingos, situado nas proximidades dos demais bairros, mas cada vez mais distante do centro da cidade e mais perto dos limites de expansão urbana, com cerca de oito mil lotes.

Até essa fase da formação da Região Noroeste, o Estado agiu de duas maneiras. $\mathrm{Na}$ fase Esperança, ele atuou de maneira repressiva e opressora para inibir o crescimento do movimento em prol da moradia e da propriedade privada, ou seja, no primeiro momento, "chegou com mão forte e usou de todos os meios para se impor enquanto instituição poderosa que interfere na vida das pessoas físicas e jurídicas" (MOYSÉS, 2004, p. 294-295). Na fase Finsocial, o Estado mudou o discurso, passando a agir de maneira assistencialista. Para Moysés (2004, p. 302), nos bairros decorrentes da ação estatal e, em nossa análise, equivalentes à fase Finsocial, a ação possuía o objetivo de desmantelar o movimento das ocupações:

A implantação dos loteamentos Vila Finsocial, Vila Mutirão e Jardim Curitiba se constituiu uma estratégia que tinha como objetivo desmantelar a articulação que se vinha criando em torno da luta pela terra, mas também acabou assumindo caráter de segregação social e espacial. A população assentada pelo poder público era, na sua totalidade, pobre, empregada ou mal empregada, jovem, nômade, possuía um perfil sócio-econômico que a distinguia dos chamados "incluídos".

Há de se destacar que houve um distanciamento dos loteamentos dos bairros onde se concentrava a maior quantidade dos postos de trabalho:

No entanto, não se pode ignorar que, ao criar melhores condições de sobrevivência desses novos loteamentos, o poder público distanciou essas populações do mercado de trabalho (o que as obrigou a percorrer longas distâncias) e não criou alternativas locais de emprego. Privando-as de relações de sociabilidade, assentou-as em loteamentos nos quais lhes foi também exigida força de trabalho na melhoria da habitabilidade de suas futuras moradias, além de uma pequena contrapartida financeira, como forma de pagamento para amortizar os custos dos investimentos realizados. (MOYSÉS, 2004, p. 318).

Em síntese, a ação estatal na fase Finsocial foi uma maneira de desarticular os movimentos de luta pela moradia e, com os assentamentos urbanos, definiu um distanciamento desse grupo de trabalhadores do mercado de trabalho, colocando-os a uma condição urbana precária. Ainda assim, as possibilidades garantidas a partir da definição dos assentamentos facilitaram a "obtenção de vagas na escola para os filhos, de novas amizades e de novas relações de vizinhança” (MOYSÉS, 2004, p. 318). 


\section{Vitória: a fase de ampliação do espaço, de 1988 a 2001}

Na etapa Vitória, o comércio da região se fortalece, mas ainda não se diversifica. A partir da luta coletiva e da ação estatal com a criação de assentamentos urbanos, outros bairros foram surgindo na Região Noroeste, principalmente a partir de 1992. Os loteamentos estabeleceram-se mais por uma pressão da regularidade do que por uma intenção do poder público numa ação pela moradia popular, de novo destacando o fator eleitoreiro das ações governamentais, como discutido por Freitas (2007). O Conjunto Jardim Primavera se constituiu num dos bairros mais particulares da região nessa fase, porque se encontrava além da zona de expansão urbana, sendo localizado na zona rural goianiense. Foi implantado pelo governo estadual e derivado da Fazenda São Domingos, a partir de 1994, sendo disponibilizado e distribuído em pouco mais de dois mil lotes.

De acordo com Cruz (2006), o Conjunto Primavera era um dos bairros mais carentes de infraestrutura física da Região Noroeste. Até o início de 2000, não contava com água tratada, sendo o abastecimento feito por poços (cisternas), ainda mais propenso a doenças porque não dispunha de esgotamento sanitário. Apenas a avenida principal do Conjunto era pavimentada.

O Conjunto Estrela D'Alva originou-se de um loteamento clandestino, formado a partir do parcelamento por chácaras que possuíam múltiplos proprietários. Tinha pouco mais de dois mil lotes, aprovados pelo Decreto $\mathrm{n}^{\circ} 1.828$, de 16 de setembro de 1998. O Conjunto Estrela D’Alva também possuía uma precária infraestrutura física em 2000. Dispunha de água tratada, porém faltava-lhe esgotamento sanitário, um reflexo da região. Era carente de áreas públicas, o que dificultava a instalação de instituições públicas e comunitárias.

O Parque Tremendão ainda não havia sido regularizado em 2000, mesmo sendo proveniente da iniciativa privada, tratando-se de um novo parcelamento de chácaras com aproximadamente quatro mil lotes, segundo Cruz (2006).

O Bairro Morada do Sol é outro exemplo de um parcelamento de chácaras de recreio que resultou num loteamento com quase três mil lotes nessa fase, de acordo com Cruz (2006). Ainda não estava regularizado em 2000. Esse bairro já esteve em situação bem mais precária. Suas ruas, no início da década de 1990, eram intransitáveis até mesmo para os pedestres. Sua avenida principal, a Avenida Mangalô, liga o bairro ao prolongamento da Avenida Goiás, no Residencial Recanto do Bosque, saída para o Jardim Nova Esperança.

Vale ressaltar que o Conjunto Estrela D'Alva, o Parque Tremendão e o Morada do Sol derivam de parcelamentos de chácaras cujos proprietários venderam lotes sem a regularização na Prefeitura, razão por que há ainda inúmeros imóveis sem escritura.

O Residencial Recanto do Bosque é o bairro mais bem-provido de benfeitorias na fase Vitória, mesmo estando ainda em processo de venda dos lotes (CRUZ, 2006). Quanto à infraestrutura, é um dos loteamentos com melhor situação no período, porque foi planejado desde o início, seja no que diz respeito à questão urbana, seja ambientalmente. Sua principal avenida, a Avenida Mangalô, foi escolhida pelo governo municipal para 
abrigar um dos terminais de integração do transporte coletivo, o Terminal Recanto do Bosque, extinguindo o terminal do setor Balneário Meia Ponte e permitindo a integração dos bairros da região.

\section{Triunfo: a fase mais recente das mudanças socioeconômicas, de 2002 a 2010}

As mudanças nas áreas urbanas, sobretudo posteriores à década de 1980, em face dos problemas relacionados à desigualdade social e à ausência de planejamento nas cidades, proporcionaram importantes discussões. Em 2001, pela Lei no .10 .257 , de 10 de julho, foi regulamentado o Estatuto da Cidade, normativa que possui como objetivo garantir ao cidadão seus direitos fundamentais necessários à vida urbana. $\mathrm{O}$ artigo 182 do Estatuto das Cidades dispõe sobre a responsabilidade dos municípios no que diz respeito aos direitos dos cidadãos na cidade, exigindo a elaboração do Plano Diretor Municipal como forma de ordenamento territorial.

Para Maricato (2010, p. 6), “o Estatuto da Cidade vai além de um conjunto de normas para a terra urbana, assume as diretrizes para o planejamento urbano, a regulação e a participação social". Assim, a fase Triunfo inicia-se um ano após a instituição dessa importante normativa e tem como recorte o intervalo de 2002 a 2010.

Vale assinalar que, em 2002, inicia-se, no país, o governo Lula, que constituiu um marco no que se refere às políticas públicas de transferência de renda. Sobre a temática, Cassini (2011, p. 22) afirma:

As políticas sociais do governo Lula, através de programas de transferência de renda como o Bolsa Família, constituem uma tentativa de minimizar os efeitos da pobreza. Visam proporcionar, a milhares de famílias brasileiras, que possam ter condições de aumentar seus rendimentos (por vezes, trata-se, na verdade, da única renda de que dispõem) para a aquisição de bens de consumo.

Os programas de transferência de renda e os programas de habitação serão importantes para a fase Triunfo. A melhoria no poder aquisitivo das famílias permitiu não só reformas nas casas, mas também a aquisição da casa própria e o consequente abandono dos aluguéis. Com o Programa Minha Casa Minha Vida, as famílias que não possuíam moradia própria nas fases anteriores tiveram a oportunidade de adquiri-la. De acordo com o Conselho Regional dos Corretores de Imóveis (Creci), entre 2009 e 2010, num período de dez meses, quase dobrou a quantidade de condomínios horizontais em Goiânia, por exemplo.

A média do metro quadrado de casas em condomínios horizontais goianienses chegou a R \$2.127,34, em novembro de 2010, sendo que a Região Noroeste apresentou o metro quadrado mais barato do estudo. $\mathrm{O}$ aumento da oferta de casas é justificado, no estudo, pela cultura do goianiense de baixa renda em preferir a habitação horizontal a vertical, uma vez que esses empreendimentos são voltados para esse grupo, o que explica o aumento de sua oferta.

A fase Triunfo é marcada também pela consolidação do comércio local, que passa a se diversificar, em virtude do aumento de farmácias, lojas de calçados, roupas, vidraçaria, papelarias, restaurantes, imobiliários etc. 
Até o início de 2014, a Região Noroeste não contava com serviço bancário. Essa situação obrigava deslocar-se até a Região Oeste, antiga parte da Região Mendanha, para ter o atendimento no Banco do Brasil, na Avenida Perimetral Norte, ou recorrer aos Bancos 24 horas, instalados em supermercados de diferentes bairros.

As casas lotéricas, que oferecem serviços de pagamento de boletos, contas básicas, como água e energia, além de saques bancários, tiveram sua implantação tardia, posterior ao ano de 2005. No decorrer do ano de 2014, foi ativada uma agência da Caixa Econômica Federal na Região Noroeste e em 2015 houve a abertura de uma agência do Banco do Brasil. Recentemente a Região Noroeste recebeu um posto do Vapt Vupt, com serviços públicos estatais e municipais, disponibilizado no Shopping Mangalô, localizado na Avenida Mangalô.

A Região Noroeste era reconhecida pelo lixo espalhado nos bairros em seus primórdios, mas já não se reproduzem ali as moradias de lona, “o lixo virou cimento, que virou alvenaria, que virou pavimentação e que gerou um novo centro urbano dentro de Goiânia" (SILVA, 2014, p. 84).

Essa fase equivale também à segunda fase da expansão urbana do município de Goianira (ANJOS, 2009). Com o deslocamento dos interesses imobiliários para a Região Noroeste, ocorreu a intensificação do processo de conurbação entre os municípios de Goiânia e Goianira, processo semelhante ao verificado nas áreas de expansão de Goianira.

No caso de Goianira [...] a partir do final da década de 1970 novos loteamentos
populares surgem às margens da GO-070. Houve um considerável aumento
de população do município, ao passo que se intensificaram as ligações com
Goiânia. Porém os loteamentos que surgiram na década de 1990 não continuaram
o processo, mas contribuíram para o adensamento da porção nuclear da cidade e
para a proliferação de lotes vazios por toda a cidade. O surgimento dos bairros
do foco conurbatório, por outro lado, apesar de estarem localizados às margens
da GO-070, traz características de motivação e ocupação bem diferentes dos
bairros de Goianira, sendo mais afeitos aos bairros da Região Noroeste de
Goiânia. (ANJOS, 2009, p. 63).

Entre os anos 2000 e 2010, é possível perceber a ampliação da mancha urbana entre Goiânia e Goianira. Observamos na Figura 1 o aumento da densidade urbana na Região Noroeste no referido período e o processo de conurbação entre os dois municípios. Há de se destacar as duas fases de ocupação do município de Goianira: a primeira entre os anos de 1996 e 2000; e a segunda entre 2001 e 2008. O bairro Conjunto Primavera, em Goiânia, consistia em uma área urbana isolada, ou seja, uma área distante da área urbana contínua, afastado na área rural goianiense.

A GO-070 viabilizou essa dinâmica, visto que os bairros acompanharam a rodovia. $\mathrm{Na}$ fase mais recente, os bairros se distanciam do eixo viário. O processo de ocupação entre os bairros da Região Noroeste e o município de Goianira teve primeiramente um padrão nuclear, ocorrendo em pequenas áreas dispersas, seguiu com um padrão linear, acompanhando o trajeto da rodovia, e, por fim, um padrão complexo (ANJOS, 2009). Esse padrão complexo teve uma primeira fase, no início dos anos 2000, 
quando ainda não estava consolidado o processo de conurbação entre os municípios de Goiânia e Goianira. A segunda fase do padrão complexo corresponde à conurbação entre os municípios, que se dá quando ocorre o contato do Jardim Primavera (Goiânia) com os Residenciais Triunfo I e III (Goiânia) e Residencial Triunfo II (Goianira).
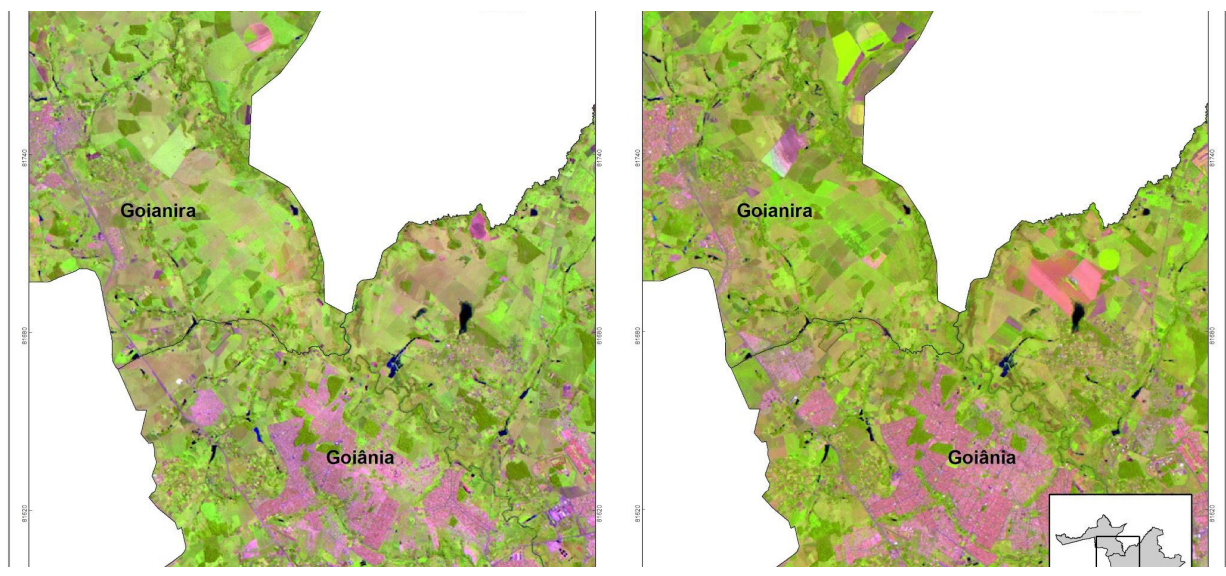

Figura 1. Processo de conurbação entre os municípios de Goânia e Goianira (Goiás) - 2000 e 2010.

Fonte: Cruz (2015, p. 87)

Mesmo com o olhar do setor imobiliário para a região e a valorização dos imóveis, as propagandas dos empreendimentos asseguram um excelente investimento na Região Norte, ou seja, sem referência a Noroeste, visto que o vínculo com a criminalidade ainda a acompanha. A nova configuração da região, no que se refere aos empreendimentos imobiliários, são os condomínios fechados para baixa e média renda, fato que carece ser amplamente estudado por aqueles que estimam conhecer mais sobre a dinâmica atual. Em síntese, a ocupação da Região Noroeste inicia-se na parte mais próxima ao centro de Goiânia e em cada fase vai se distanciando a área de ampliação urbana até a conurbação com Goianira, como dissemos.

Tremendão: a fase intermediária, de 1979 a 2010

Nessa fase intermediária (Tremendão) do percurso histórico da Região Noroeste, como em toda ocupação, há uma relação de criminalização da luta. E a consequência quase imediata é a vinculação dos moradores a nomes pejorativos, mesmo com nomenclatura justificada em outros motivos. Ainda que os relatos associem o nome do Bairro Tremendão ao álbum do cantor Erasmo Carlos, bastante conhecido durante a Jovem Guarda, fora desse contexto ele adquire outra interpretação, quase sempre depreciativa. A escolha do nome da fase Tremendão remete à associação dos bairros de origem de ocupações urbanas ou simplesmente os bairros de baixa renda com a ilegalidade, a criminalidade ou mesmo com a transgressão às leis, elementos que permearam a região desde sua origem. 
Quando um espaço penalizado se torna ou tem a possibilidade de se tornar fixo na paisagem urbana, ele tende a ser circundado por um discurso de descrédito, ampliandose os estigmas negativos, geralmente ligados à pobreza (WACQUANT, 2006). Esses elementos, chamados de "infâmia territorial" ou "descrédito territorial", se instalam nas esferas políticas e sociais (WACQUANT, 2006). No caso de Tremendão, corresponde a uma fase intermediária, que tem ligação com o imaginário urbano:

\begin{abstract}
A topologia simbólica dos lugares estigmatizados da urbe associa assim a pobreza ao perigo e à contravenção, estabelecendo ainda correlação entre cor, condição social e comportamento desviante. No caso específico da maloca, procede-se a uma associação entre uma palavra de um determinado contexto para outro, mas onde o sentido depreciativo se acentua para potencializar a estigmatização. (PESAVENTO, 1999).
\end{abstract}

Em seu estudo sobre o espaço urbano e a criminalidade na Região Noroeste, Jesus Júnior (2005, p. 61) afirma que a região foi "um dos primeiros bolsões de miséria da metrópole". Com o grande crescimento populacional e a consequente expansão de bairros, a região passou a ter uma população com uma das menores rendas per capita da cidade de Goiânia e alta concentração de migrantes inter-regionais, graças a programas de moradia iniciados na década de 1980. Ademais, a infraestrutura básica era deficitária e existiam altos índices de violência.

Diante desse cenário, historicamente, muitas famílias se opunham a residir na Região Noroeste, quando eram convidadas, haja vista a desigualdade social espacializada na cidade e os estigmas territoriais. O contraste entre os bairros com "signos da alta renda" e os exemplos de "precariedade social" nos ajuda a compreender a relação entre baixa renda e os elementos pejorativos que lhes são atribuídos, demonstrando uma consequência inevitável, a violência criminal (JESUS JÚNIOR, 2005, p. 42).

A Vila Finsocial recebe o nome de um programa do governo federal para "fins sociais" e tem sua nomenclatura estigmatizada e associada a elementos discriminatórios, transformada no "fim da sociedade".

A Vila Mutirão é a que tem a questão mais emblemática no contexto. $\mathrm{O}$ marketing do dia da construção das mil casas só foi manifestado na primeira etapa. Nas duas etapas posteriores (II e III), com o mesmo sentimento discriminatório da anterior e da região e com a dificuldade dos moradores em conseguir emprego, dada sua origem em ocupações ou assentamentos, decidiu-se, em plebiscito, pela mudança no nome dos bairros. Após aprovação, surgem o Jardim Novo Planalto e o Jardim Liberdade.

A aparente suavização ou a tentativa de desvincular o medo relacionado aos moradores da Região Noroeste tornou-se um destaque no período que vem desde a etapa Esperança até o Triunfo. Nomes ligados às belezas naturais ou relacionados à tranquilidade, como no caso do Residencial Recanto do Bosque, do Alto do Vale, do Morada do Sol e do Estrela D'Alva, são ainda mais perceptíveis nos residenciais e condomínios horizontais que se multiplicavam.

Longe de atribuir essa estigmatização somente à Região Noroeste, as discussões indicam que a população de ocupação, em algum momento, teve o contato com a 
identificação da fragmentação social em relação ao local de residência, como é o caso de bairros que, atualmente, possuem intensa valorização imobiliária, mas com histórico de ocupação: "A ocupação das margens do córrego Areião era conhecida por Macambira, cuja população era marginalizada, tida como violenta. O nome do bairro significava, em expressão popular, o fim do mundo" (OLIVEIRA; PEIXOTO, 2009, p. 60).

Wacquant (2006) refere que, apesar da estigmatização, ocorre o desenvolvimento da identidade em relação a esses espaços. Em sua tese, Jesus Júnior (2005, p. 139) discorda da vinculação da ideia de violência aos bairros da Região Noroeste com a história das ocupações. Para esse autor, a violência urbana tem a ver com a desigualdade social e suas derivações, como o desemprego. No entanto, na opinião do autor, nem mesmo com a melhoria nas condições de vida, saúde, emprego e crescimento econômico da região esse estigma foi dissipado.

\section{Uma nova classe trabalhadora}

Aquecida pelas discussões de uma nova classe média, a fase Triunfo tem uma característica diferenciada das etapas anteriores do processo de formação da Região Noroeste de Goiânia (Figura 2). Em outros momentos, por exemplo, as moradias, em sua maioria, eram feitas de lona, de forma improvisada, e com a exposição da família a condições de insalubridade, como é o caso das casas da Vila Mutirão.

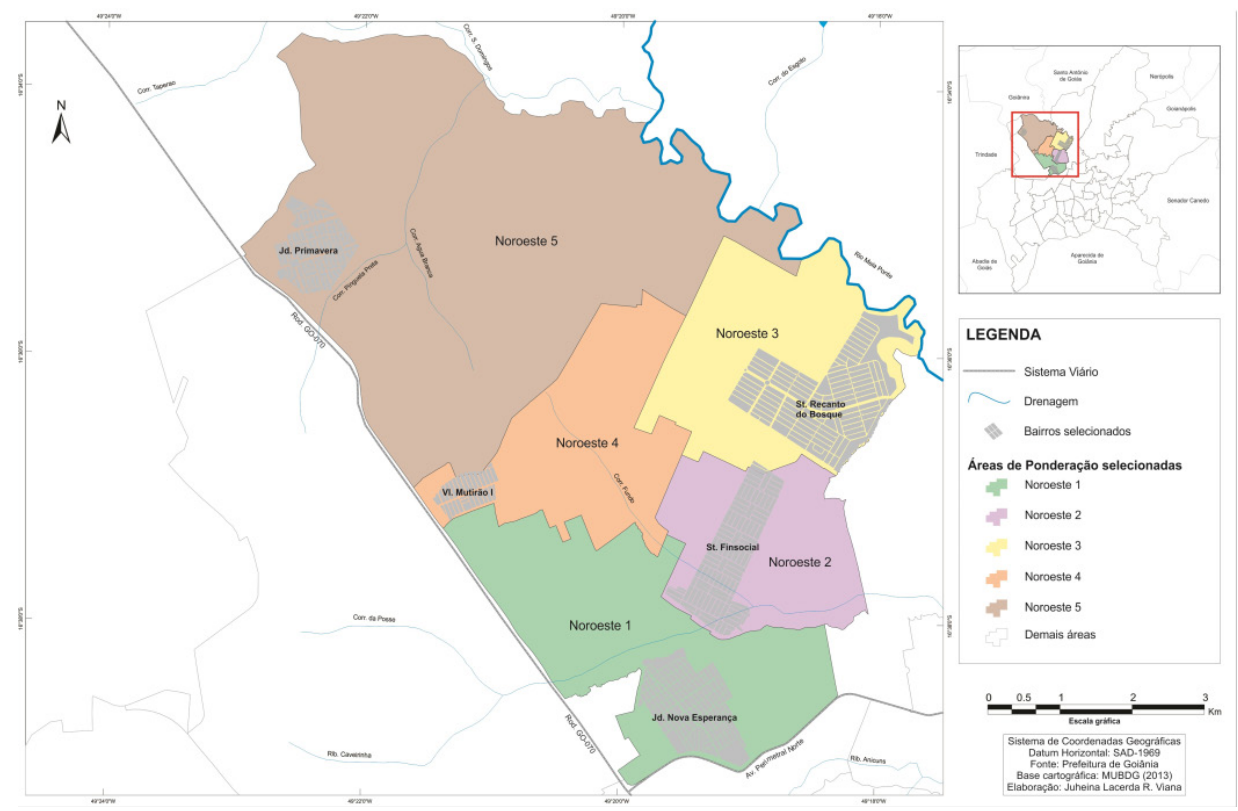

Figura 2. Região Noroeste de Goiânia: por áreas de ponderação e bairros selecionados - 2010 Fonte: CRUZ (2015, p. 94). 
Em 2010 mais de $83 \%$ das moradias eram de alvenaria, e as que não tinham revestimento externo, reboco ou chapisco não chegavam a 17\%. Mesmo havendo domicílios $(0,1 \%)$ construídos por material que não era possível identificar, é perceptível uma melhoria na estrutura das casas, bem como uma diminuição do número de moradores por dormitório.

Um fator importante para as discussões acerca de uma nova classe está na frequência da população à creche ou escola. Levando em consideração que o IBGE entende como escola as instituições de ensino básico e superior, o número de moradores frequentes não chegou a $30 \%$, índice bem inferior aos pouco mais de $59 \%$ que um dia frequentaram e em 2010 estavam afastados das escolas. A maioria dos frequentes $(54,72 \%)$ tinham mais de 25 anos e em sua maioria cursavam o ensino fundamental. A escolaridade da população também apresentou avanços em comparação com as etapas de ocupação anteriores, sobretudo quanto ao número de frequentes nas classes de ensino médio $(21,09 \%)$ e do ensino superior $(3,39 \%)$.

Acerca da discussão se haveria uma nova classe média, um dado a ser considerado refere-se à escolaridade e ao percentual de pessoas que não tinham instrução ou que não haviam concluído o ensino fundamental, o que representa mais de $51 \%$ dos moradores. Mesmo com pouco mais de $7 \%$ da população matriculados no ensino superior, há um grande universo de pessoas, chefes de família, que não conseguiam, em 2010, sequer escrever ou reconhecer o próprio nome.

Definitivamente os postos de trabalho formais aquecem a discussão. De acordo com Oliveira (1999) e Moyses (2004), nas primeiras fases da ocupação os moradores eram em grande maioria trabalhadores sem vínculo empregatício registrado. Em 2010, mais de $63 \%$ dos trabalhadores possuíam carteira assinada, índice que, se somado aos $25,22 \%$ que trabalhavam por conta própria, mostra uma dinâmica diferenciada e semelhante à apresentada no país. Mas na triangulação dos dados de escolaridade, jornadas de trabalho, padrão de consumo e renda, somos levados a classificar a Região Noroeste como representante da nova classe trabalhadora. Isso sem contar que mais de $43 \%$ da população economicamente ativa tinham jornada de trabalho entre 40 e 44 horas semanais, ocupando sobretudo os setores da indústria e de serviços.

Como a maioria dos trabalhadores estava lotada em instituições localizadas em Goiânia, outro fator a destacar é o tempo de deslocamento do trabalhador entre a moradia e o trabalho. Cerca de $41 \%$ dos trabalhadores destinavam até duas horas por dia para deslocamento ao trabalho. Mas os trabalhadores do ponto mais extremo da Região Noroeste em relação ao centro chegavam a destinar mais de quatro horas de sua moradia ao trabalho e com retorno diário. Em números gerais, esse morador chegava a destinar até 24 horas por semana, num total de 44 dias por ano, cerca de mais de 1.000 horas anuais para o deslocamento, assegurados os trinta dias destinados às férias.

A renda e o padrão de consumo certamente são critérios que mais geram contradição nas discussões acerca de uma nova classe. Quanto à renda per capita, adotada no estudo, o percentual de domicílios sem rendimento tanto na Região Noroeste como no todo de Goiânia é equivalente a cerca de 3\%. Esse dado pode ser explicado 
pelas políticas de distribuição de renda por intermédio dos programas sociais em âmbito federal.

Para ser enquadrada como nova classe média a família precisava receber, em 2010, entre R\$ 291 e R\$ 1.024 per capita (ocasião em que o salário mínimo era de R\$ 510 reais). Como 78,25\% dos domicílios tinham renda acima de meio salário mínimo, valor bem próximo dos $\mathrm{R} \$ 2$ 291, podemos inferir que, se levado em consideração esse critério exclusivamente, a Região Noroeste de Goiânia representa uma nova classe média. Soma-se a esse fator o percentual de domicílios com bens de consumo: $96,06 \%$ com televisão, 96,46\% com geladeira, 76,25\% com rádio, 94,88\% com algum serviço telefônico e cerca de um terço com motocicleta, automóveis e computadores, sendo esse último com a maioria tendo acesso à internet $(61,31 \%)$.

\section{Considerações finais}

Mesmo com esses dados e discussões, consideramos que há uma classe renovada, mas não uma classe média tradicional. Trata-se de uma classe trabalhadora com renda e padrão de consumo ampliado, mas com longas jornadas de trabalho e deslocamento moradia-trabalho, o que, inclusive, dificulta a conclusão do ensino básico, justificada por mais de quarenta horas semanais de trabalho e até 24 horas semanais destinadas ao transporte para essa finalidade. Apesar do esforço do trabalhador, a formação educacional necessária para uma melhoria na renda familiar é ameaçada pelo quantitativo de horas ocupadas em atividades essenciais para a manutenção da família.

Estudar a Região Noroeste de Goiânia foi elucidativo para compreender como as mudanças socioeconômicas do país caminharam. Como vimos, a origem da região estudada remonta a uma ocupação urbana cuja população caracterizava-se pela extrema pobreza, a maioria sem escolaridade e sem vínculo empregatício registrado. As intervenções governamentais para moradia e transferência de renda, por exemplo, foram algumas ações importantes para compreender essa dinâmica. Assim, como evidenciamos neste estudo, a Região Noroeste de Goiânia deixa de ser considerada como grande representante da extrema pobreza de Goiânia para ter hábitos e comportamentos semelhantes aos de uma nova classe trabalhadora.

\section{Referências}

A VOZ DOS TRABALHADORES. Goiânia, ano I, n. 1, out. 1979. Disponível em: < http://www.cpvsp.org.br/ >. Acesso em: 15 mar. 2014.

ALVES, M. de L. Goiânia: cidade de migrantes. 2002. Dissertação (Mestrado em Sociologia) - Faculdade de Ciências Humanas e Filosofia, Universidade Federal de Goiás, 2002.

ANJOS, A. F. dos. A dinâmica intraurbana de Goianira no contexto da Região Metropolitana de Goiânia. 2009. Dissertação (Mestrado em Geografia) - Instituto de Estudos Socioambientais, Universidade Federal de Goiás, Goiânia, 2009. 
CASSINI, Lucas Arcanjo. Concepção de pobreza subjacente ao programa Bolsa Família nos governos Lula: rumo à construção da cidadania? Revista Sociedade em Debate, Pelotas, v. 7, p. 69-86, 2011. Disponível em: <http://www.rle.ucpel.tche.br/index.php/ rsd/article/view/697/621>. Acesso em: 7 fev. 2015.

CHAVEIRO, E. F; CALAÇA, M; REZENDE, M. C. da S. A dinâmica demográfica de Goiás. Goiânia: Ed. Ellos, 2009.

CRUZ, R. C. da. Região Noroeste de Goiânia: um resgate do lugar. Monografia (Geografia) - Instituto de Estudos Sócio-Ambientais, Universidade Federal de Goiás, Goiânia, 2006.

- A Região Noroeste de Goiânia: de grande bolsão de pobreza à nova classe trabalhadora. Dissertação (Geografia) - Instituto de Estudos Socioambientais, Universidade Federal de Goiás, Goiânia, 2015.

DIÁRIO DA MANHÃ. As invasões de Goiânia. Goiânia, 1982.

FREITAS, S. A. Habitação popular em Goiânia: Vila Mutirão, mil casas em um dia. Dissertação (Mestrado) - Universidade Federal do Rio Grande do Sul, Porto Alegre, 2007.

GOHN, M. da G. Teoria dos Movimentos Sociais: paradigmas clássicos e contemporâneos. 7. ed. São Paulo: Edições Loyola, 2007.

JESUS JÚNIOR, R. S. de. Espaço e criminalidade na Região Noroeste de Goiânia, $G O$ : a visão dos sujeitos sociais (2004). 2005. Dissertação (Mestrado em Geografia) Universidade Federal de Uberlândia, Uberlândia, 2005.

LEFEVRE, H. A revolução urbana. Tradução: Sérgio Martins. Belo Horizonte: UFMG, 1999.

MARICATO, H. O estatuto da cidade periférica. In: CARVALHO, C. S.; ROSSBACH, A. O Estatuto da Cidade: comentado. São Paulo: Ministério das Cidades, 2010.

MOYSÉS, A. Goiânia, metrópole não planejada. Goiânia: Ed. UCG, 2004.

OLIVEIRA, A. F. de. Do pântano ao jardim: uma nova esperança. 2002. Dissertação (Mestrado) - Faculdade de Ciências Humanas e Filosofia, Universidade Federal de Goiás, Goiânia, 2002.

OLIVEIRA, A. M. V. de; PEIXOTO, E. R. Jardim Goiás, o bairro de um dono. In: SIMPÓSIO NACIONAL DE HISTÓRIA, 15., 2009, Fortaleza. Anais... Fortaleza: Anpuh, 2009.

OLIVEIRA, A. G. de. A reprodução da exclusão social em áreas de expansão urbana: um estudo de caso em assentamentos urbanos na Região Noroeste de Goiânia (19801998). Dissertação (Mestrado) - Instituto de Estudos Sócio-Ambientais, Universidade Federal de Goiás, Goiânia, 1999.

PESAVENTO, S. J. Lugares malditos: a cidade do "outro" no Sul brasileiro (Porto Alegre, passagem do século XIX ao século XX). Revista Brasileira, São Paulo, v. 19, n. 37, 1999. Disponível em: <http://www.scielo.br/scielo.php?pid=S0102- 
01881999000100010\&script=sci_arttext $>$ http://www.scielo.br/scielo.php?pid=S010201881999000100010\&script=sci_arttext. Acesso em: $1^{\mathrm{o}}$ jan. 2015.

RODRIGUES, A. M. Moradia nas cidades brasileiras. São Paulo: Contexto, 1994.

SANTOS, M.; SILVEIRA, M. L. Território e sociedade no início do século XXI. Rio de Janeiro: Record, 2001.

SILVA, A. F. da. Goiânia a Noroeste: da ocupação ao novo centro urbano. 2014. Dissertação (Mestrado) - Faculdade de Arquitetura e Urbanismo, Universidade de Brasília, Brasília, 2014.

WACQUANT. L. A estigmatização territorial na idade da marginalidade avançada. Paris: La Découverte, 2006. Disponível em: <http://ler.letras.up.pt/uploads/ficheiros/4618. pdf>. Acesso em: 27 set. 2015.

\section{Renatha CÂNDIDA DA CRUZ}

Doutoranda em Geografia pela Universidade Federal de Goiás - UFG. Mestra e graduada em Geografia pela Universidade Federal de Goiás - UFG. É professora de Geografia no Instituto Federal de Goiás - Câmpus Uruaçu e membra do Grupo de Pesquisa Território e Fluxos do Instituto de Estudos Socioambientais - IESA. UFG Campus Samambaia, Caixa Postal 131, Cep: 74001-970, Goiânia-GO, Brasil.

E-mail: renathacruz@gmail.com

\section{Jỗo Batista de Deus}

Doutor em Geografia pela Universidade de São Paulo - USP. Mestre em Geografia Humana pela Universidade de São Paulo - USP. Graduado em Geografia pela Universidade Federal de Goiás - UFG. Atualmente é professor efetivo do Instituto de Estudos Socioambientais - IESA - onde também atua no Programa de Pesquisa e Pós-Graduação em Geografia. É coordenador do Grupo de Pesquisa Território e Fluxos.

UFG Campus Samambaia, Caixa Postal 131, Cep: 74001-970, Goiânia-GO, Brasil.

E-mail: deus.joao@gmail.com 